\title{
Study of Protective Action of Spondias pinnata Bark extract on Rat Liver and Kidney against Etoposide Induced Chemical Stress
}

\author{
Beena Shetty, Gayathri Rao*, Abhineetha, Niha Banu, Preethika and Sudarshan Reddy \\ Department of Biochemistry, Kasturba Medical College, Mangalore, Manipal University, India.
}

\begin{abstract}
Introduction: System injury, manifested as metabolic dysfunction is a common side effect of chemotherapy. Chemical stress on hepatic and kidney cells can be evaluated by biochemical analysis, including serum aminotransferases, glutathione levels and extent of lipid peroxidation. Combined treatment of chemotherapy along with the natural products such as phytochemicals may be a newer approach to reduce the side effects and betterment of chemotherapy. Objective: The present study was conducted to assay kidney and liver associated parameters on animals exposed to etoposide, and the protective effect of different doses of Spondias pinnata bark extract on normal cells. In this study, total 24 male Wistar rats (either sex) aged between 60 to 90 days were considered. Each group consisted of six rats. Levels of Alanine and Aspartate aminotransferases were estimated using semi-auto analyser and GSH, GST, TAO and LPx by spectrophotometry. Results and Conclusion: Data analyzed using Graph Pad 5.0. Variation in the analyzed parameters were found between control,
\end{abstract}

chemotherapy and Spondias pinnata groups. Results of the study show that significant increase in TBARS levels indicative of etoposide induced oxidative stress could be prevented by treatment with S. pinnata. GST levels also support the preventive action of $S$. pinnata against etoposide induced stress. However, TAO and transaminases remain unaltered in the study groups.

Key words: Etoposide, GSH, GST, LPx, Spondias pinnata.

Address for Correspondence:

Dr. Gayathri Rao, Department of Biochemistry, Centre for Basic Sciences, Kasturba Medical College, Bejai, Mangalore, India.

Phone no: 9448951498

Email: gayathri.rao@manipal.edu

DOI : 10.5530/pj.2016.1.5

\section{INTRODUCTION}

Cancer constitutes the largest cause of mortality in the world and claims over 6 million lives every year. ${ }^{1}$ It is a disease in which cellular growth regulatory networks are disrupted. ${ }^{2}$ An extremely promising strategy for cancer prevention in humans today is chemotherapy, which is defined as the use of synthetic or natural agents (alone or in combination) to block the development of cancer. ${ }^{3}$

Most of the anticancer drugs have side effects on human normal cells when they are used to treat tumor cells. ${ }^{4}$ Etoposide has been recognized as active compound used potentially for treatment of various cancers. This compound can be used for further research due to its bio-molecular mechanisms that target cancer cell proliferation. Chemotherapeutic agents, like etoposide, kill not only cancer cells, but also the rapidly replicating liver and kidney cells, causing tissue damage associated with the imbalance in enzyme system. Therefore along with the cancer drugs supportive medication is needed to reduce above mentioned toxic effects on normal cells.

Spondias pinnata (S. pinnata) is a deciduous tree distributed in India, Sri Lanka and South-East Asian countries. The phytochemistry of this plant has been studied. ${ }^{5}$ The gum exudate of the species has been found to contain acidic polysaccharides. ${ }^{6}$ A crude extract of $S$. pinnata has been reported to show antibacterial activity also. ${ }^{7}$ In ethno-medicine, bark juice of $S$. pinnata is prescribed as a remedy for dysentery. ${ }^{7}$ It has shown antioxidant and free radical scavenging activity. ${ }^{8}$ In this study we evaluated the effects of $S$. pinnata bark extract, chemotherapeutic agent etoposide and the effect of bark extract on liver and kidney after the administration of etoposide by estimation of LPx, GSH and total antioxidant activity.

\section{SUBJECTS AND METHODS}

Adult albino rats of Wistar strain were used for the study. Animals weighing about 220-250 g obtained from central animal house, Kasturba Medical College, Mangalore, India, were used. The animal studies were carried out upon institutional animal ethical committee approval.
Animals were acclimatized for a period of two-weeks and were then treated. They received standard pellet and water ad libitum. Rats were coded in groups of two per cage. Single dose of etoposide (60 mg/kg, i.p) was administered.

Animal grouping $(\mathrm{n}=6)$ :

Group 1 Normal control.

Group 2 The rats received etoposide alone (i.p) in a single dose of $60 \mathrm{mg}$ per kg body weight.

Group 3 The rats received etoposide (i.p) followed by S. pinnata bark extract in a dose of $100 \mathrm{mg}$ per kg body weight orally once in a day from $0 \mathrm{hr}$ to $72 \mathrm{hrs}$.

Group 4 The rats received etoposide (i.p) followed by S. pinnata bark extract in a dose of $200 \mathrm{mg}$ per kg body weight orally once in a day from $0 \mathrm{hr}$ to $72 \mathrm{hrs}$.

The change in the body weight and food intake was monitored on daily basis. After $72 \mathrm{hrs}$, rats were sacrificed by cervical dislocation. The small intestine was dissected out, washed in ice-cold PBS, and blotted. For histological assessment, first part of the duodenum $(1 \mathrm{~cm})$ was fixed in formalin $(10 \%)$. The middle piece was used for assessment of biochemical parameters. Samples were immediately homogenized and stored at $-80^{\circ} \mathrm{C}$ until use.

\section{Chemicals}

Chemicals and reagents were of HPLC or analytical grade procured from Sri Durga Laboratories, Mangalore, India.

\section{Biochemical parameters}

\section{Estimation of Reduced Glutathione}

Tissue GSH concentration was estimated according to the method described by Ellman. ${ }^{9} 1 \mathrm{ml}$ of tissue homogenate was precipitated with $1 \mathrm{ml}$ of precipitating agent. The samples were centrifuged at $1,200 \mathrm{~g}$ for $15 \mathrm{~min}$ 
at $4^{\circ} \mathrm{C}$. To $1 \mathrm{ml}$ of this supernatant, $2.7 \mathrm{ml}$ of phosphate buffer and 5, 5' dithio-bis-2-nitrobenzoic acid (DTNB) was added. The yellow color that developed was read immediately at $412 \mathrm{~nm}$. The values were expressed in $\mathrm{mg} / \mathrm{gm}$ of wet tissue.

\section{Estimation of total antioxidants (TAO)}

The total antioxidants level was estimated according to the method described by Koracevic et al., 2001. ${ }^{10}$

Assay procedure: Each sample had its own control in which Fe-EDTA mixture, $\mathrm{H}_{2} \mathrm{O}_{2}$ and sodium benzoate were added after $20 \%$ acetic acid. For each series of analysis a negative control was prepared, except that sample homogenate was replaced with $0.1 \mathrm{M}$ sodium phosphate buffer, $\mathrm{pH}$ 7.4. Uric acid $(1 \mathrm{Mm} / \mathrm{L})$ was used as standard. The reaction mixture was incubated at $37^{\circ} \mathrm{C}$ for $60 \mathrm{~min}$. Then $20 \%$ acetic acid and $0.8 \%$ TBA were added and incubated for $10 \mathrm{~min}$ at $100^{\circ} \mathrm{C}$, then cooled in ice bath. The absorbance was measured at $532 \mathrm{~nm}$. The total antioxidant level was expressed as $\mathrm{m}$ moles/L.

\section{Assay of Glutathione S-Transferase (GST)}

Glutathione S-transferase was assessed by the method of Habig et al. (1974) The activity of the enzyme was determined by observing the change in absorbance at $340 \mathrm{~nm}$. The reaction mixture contained $0.1 \mathrm{ml}$ of GST, 0.1 $\mathrm{ml}$ of CDNB and phosphate buffer in a total volume of $2.9 \mathrm{ml}$. The reaction was initiated by the addition of $0.1 \mathrm{ml}$ of the homogenate. The readings were recorded every 15 seconds at $340 \mathrm{~nm}$ against distilled water blank for a minimum of three minutes. The assay mixture without the homogenate served as the control to monitor non-specific binding of the substrates. ${ }^{11}$

\section{Assay for lipid peroxidation (LPO)}

The lipid peroxidation products in the homogenates were measured through the estimation of Thiobarbituric acid reactive substances (TBARS) by the method as described by Buege and Aust, 1978 and Gayathri et al., 2000. ${ }^{12,13}$

Assay procedure: $1 \mathrm{ml}$ of tissue homogenate was precipitated with $2.5 \mathrm{ml}$ of ice cold Trichloroacetic acid (TCA). The samples were centrifuged at $3000 \mathrm{~g}$ for $10 \mathrm{~min}$. To $2 \mathrm{ml}$ of this supernatant, $0.67 \%$ of Thiobarbituric acid (TBA) was added and kept in boiling water bath for $10 \mathrm{~min}$ and cooled. The pink chromogen developed was read immediately at $532 \mathrm{~nm}$. TBARS concentration was calculated using molar extinction coefficient of chromophore $\left(1.56 \times 10^{5}(\mathrm{~mol} / \mathrm{l})^{-1} \mathrm{~cm}^{-1}\right)$ and the values were expressed in nmoles/L. Total protein concentration of tissues was measured by the method of Lowry et al., 1951.

\section{RESULTS}

Animals that received chemotherapy (Group-2) showed a significant decrease of GSH level in the liver and kidney compared to control group (Group-1 Vs group-2, $\mathrm{p}<0.05)$. Treatment with $S$. pinnata bark extract after chemotherapy (group-3 and group-4) showed a significant increase $(\mathrm{p}<0.01, \mathrm{p}<0.05)$ in GSH level when compared to group-2 (Figure 1).

No significant variation in total antioxidants level was observed in liver and kidney of the rats between the different groups (Figure 2).

Animals that received chemotherapy (Group-2) showed a significant increase of GST level in the liver and kidney compared to control group (Group-1 vs Group-2, p<0.05). Animals that received chemotherapy along with $S$. pinnata bark extract treatment (Group-2 vs Group-3: $\mathrm{p}<0.01, \mathrm{p}<0.05)$ and (Group-2 vs Group-4: $\mathrm{p}<0.05, \mathrm{p}<0.01)$ showed a significant decrease $(\mathrm{p}<0.01, \mathrm{p}<0.05)$ in GST levels (Figure 3).

The level of the Thiobarbituric acid reactive substances (TBARS) is a marker of lipid peroxidation. Animals exposed to chemotherapy showed a significant increase in TBARS level in the liver and kidney compared to control (Group-1 vs Group-2, $\mathrm{p}<0.01$ ). Animals exposed to chemotherapy

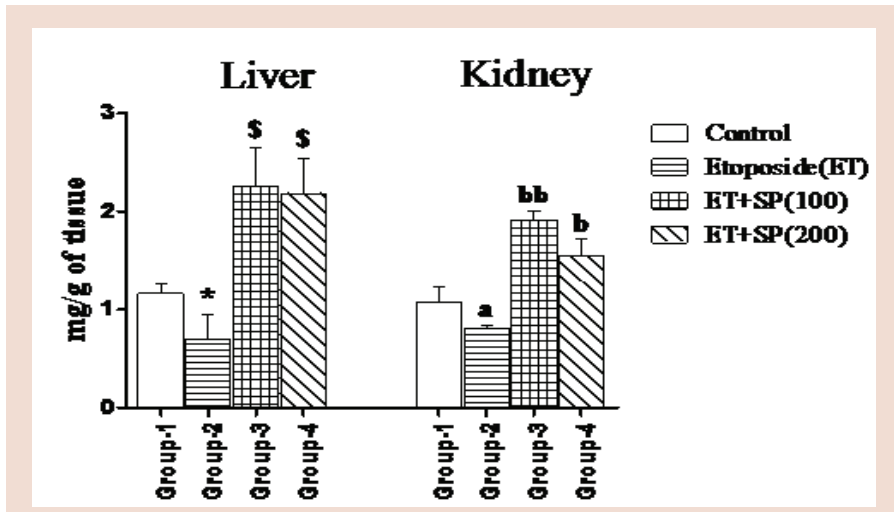

Figure 1: Reduced Glutathione level ( $\mathrm{mg} / \mathrm{g}$ of tissue) in rat liver and kidney. ANOVA significance (Bonferroni's test, each bar represents mean $\pm S E M, n=06$ ) $\mathrm{P}<0.0001$ and $\mathrm{F}=20.36$

Group-1 vs Group-2, Group-3 and Group-4, ${ }^{*} p<0.05$, ap $<0.05$

Group-2 vs Group-3 and Group-4, \$p $<0.05$, bbp $<0.01, b p<0.05$

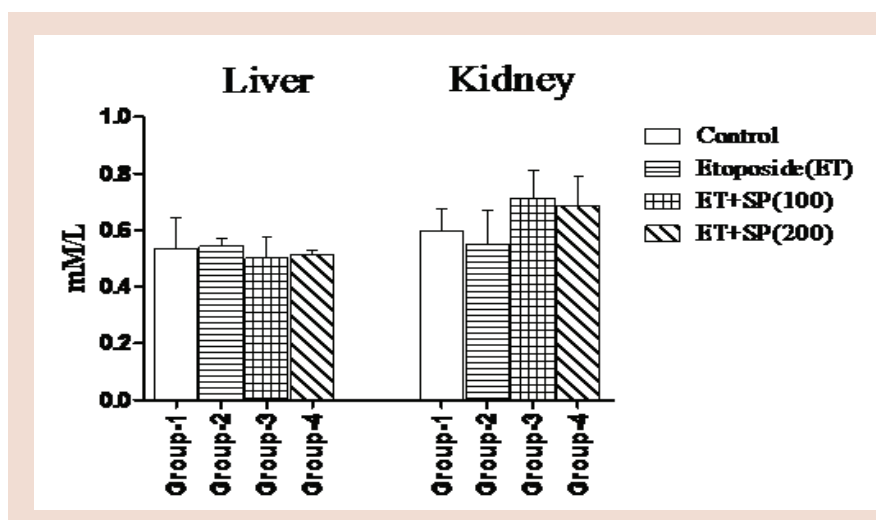

Figure 2: Effects of chemotherapy and Spondias pinnata administration on the total antioxidant level ( $\mathrm{m}$ moles/lit) in the rat liver and kidney.

ANOVA significance (Bonferroni's test, each bar represents mean $\pm S E M, n=06$ ) $\mathrm{P}=0.5610$ and $\mathrm{F}=0.8401$

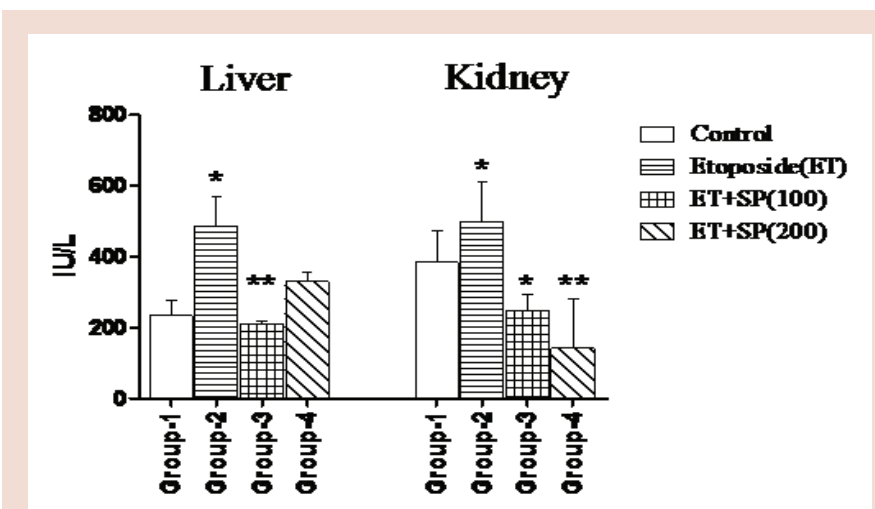

Figure 3: Glutathione S-transferase level (IU/L) in rat liver and kidney. ANOVA significance (Bonferroni's test, each bar represents mean $\pm S E M, n=06$ ) $\mathrm{P}<0.0103$ and $\mathrm{F}=6.616$

Group-1vs Group-2, Group-3 and Group-4, * $\mathrm{p}<0.05$

Group-2 vs Group-3 and Group-4, ${ }^{*} p<0.05,{ }^{* *} p<0.01$

followed by S. pinnata bark extract (Group-3 and Group-4) showed a significant decrease in TBARS level in the liver and kidney compared to etoposide control (Group-2 vs Group-3 and Group-4, p<0.05) (Figure 4). 


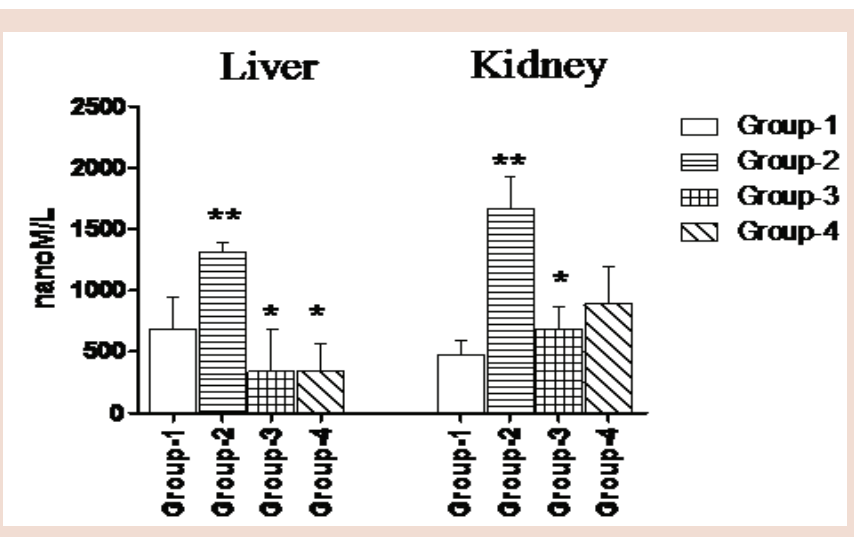

Figure 4: Effect of chemotherapy and Spondias pinnata administration on the TBARS (nanomoles/L) level in the Liver and Kidney.

ANOVA significance (Bonferroni's test, each bar represents mean $\pm S E M, n=06$ per group)

$P<0.0081$ and $F=7.012$

Group-1vs Group-3, Group-3 and Group-4, ** $p<0.01$

Group-2 vs Group-3 and Group-4, * $\mathrm{p}<0.01$

The effect of chemotherapy on levels of ALT and AST in rat liver were investigated. No statistical significance was observed in the enzyme levels between the different groups (Figure 5).

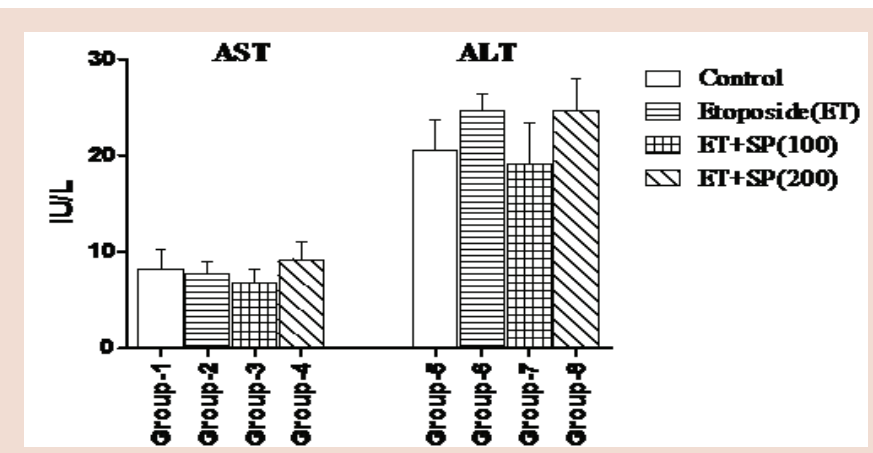

Figure 5: Effects of chemotherapy and Spondias pinnata administration on the AST and ALT levels (IU/lit) in the rat liver.

ANOVA significance (Bonferroni's test, each bar represents mean \pm SEM, $(n=06)$

$\mathrm{P}=0.7563$ and $\mathrm{F}=0.3973$

\section{DISCUSSION}

Conventional chemotherapy induces uncontrollable adverse effect and increased mortality rate in patients. This indicates that new approaches are critically needed. Literature survey shows that $S$. pinnata bark extract contains large amounts of flavonoids and phenolic compounds, exhibits high antioxidant and free radical scavenging activities. ${ }^{8}$ Among the wide range of adverse events, mucositis is commonly seen in the majority of the patients who undergo chemotherapy. Administration of $S$. pinnata bark extract has shown to attenuate the chemotherapy induced mucositis. ${ }^{14}$ It also chelates iron and has reducing power. These antioxidant properties may have impact on the damaging reactive oxygen species which are generated during chemotherapy. ${ }^{3,6}$ Introduction of cytotoxins into the system, results in the formation of reactive species which are responsible for the damage of cells, tissues and blood vessels. ${ }^{15}$
Liver being the major organ concerned with the intermediary metabolism, detoxification and excretion, chemotherapy may be a challenge for hepatocytes. Many chemotherapeutic agents and their metabolites are excreted through the kidney, hence kidneys are highly vulnerable to these agents.

The main function of GST is to detoxify xenobiotics in the liver by catalyzing the nucleophilic attack by GSH on electrophilic carbon, sulfur or nitrogen atoms of nonpolar xenobiotic substrates, thereby preventing their interaction with crucial cellular proteins and nucleic acids ${ }^{16,17}$ and thus susceptibility to various types of diseases. Numerous studies have implicated such variations seen in asthma, atherosclerosis, allergies, and other inflammatory diseases. ${ }^{17}$ An increase in the levels of GST enzyme was observed in etoposide control group compared to normal control, which is a sign of hepatic and kidney tissue damage. Results of S. pinnata intervention following etoposide treatment (Group 3 and 4) has shown that requirement of GST is less than the etoposide control (Group 2) in suggestive of restoration of normal environment of liver and kidney tissues. This could be due to the GST like protective/preventive effect of the bark extract against the etoposide induced tissue toxicity.

GSH is known to protect body tissues against oxidative damage and inflammation. The liver is the largest glutathione reservoir. Detoxification of xenobiotics or their metabolites is one of the major functions of GSH and it is essential in maintaining the intracellular redox balance and the essential thiol status of proteins. ${ }^{18}$ Decreased levels of GSH in rats exposed to etoposide in comparison with normal control is primarily by severe oxidative stress induced by chemotherapy. This could be due to either increased utilization of GSH to detoxify the drug or decreased ability of the cell to reduce GSSG to GSH or due to decreased synthesis of GSH. Accumulation of GSSG within the cytosol may lead to cell apoptosis. S. pinnata intervention brings about the restoration of GSH levels in kidney and liver tissue. Increased free radical stress disturbs the membrane lipids by their oxidation, results in the formation of products such as malondialdehyde and TBARS and will worsen normal functioning of the cells ${ }^{19}$ S. pinnata (100 and $200 \mathrm{mg} / \mathrm{kg}$ ) treatment combined with etoposide may prevent lipid peroxidation due to its antioxidant phytochemicals.

Previous studies have shown that the serum levels of ALT and AST were significantly high after chemotherapy compared to control. ${ }^{20}$ In the present study there was no significant elevation of ALT and AST levels observed in the liver tissue. It is possible that the alteration in transaminase levels depend on the type of drugs used in chemo therapy.

The main aim of this work was to study the effects of $S$. pinnata bark extract on the liver and kidney. We were able to demonstrate that some of the parameters which altered due to chemotherapy with etoposide were restored/ remained unaltered by the administration of $S$. pinnata bark extract. $100 \mathrm{mg} / \mathrm{kg}$ body weight dose of $S$. pinnata bark extract was more effective than $200 \mathrm{mg} / \mathrm{kg}$ body weight. The study also showed that there was no adverse effect on liver and kidney cells due to intervention with S. pinnata bark extract.

This proof-of-concept study represents the first report of protection against liver and kidney cellular damage following oral administration of S. pinnata bark extract in etoposide treated rats.

Therefore combining conventional treatment with $S$. pinnata bark extract may ensure better quality of life to the patient by ameliorating side effects.

\section{ABBREVIATION USED}

TBARS: Thiobarbituric acid reactivew substance, GST: Glutathione-Stransferase, GSH: Reduced glutathione, Tao: Taotal antioxidants, LPO: Lipid peroxidation. 


\section{REFERENCES}

1. Abdullaev FI, Rivera-Luna $\mathrm{V}$, Roitenburd-Belacortu, Espinosa-Aguirre. Pattern of childhood cancer mortality in Mexico. Arch Med Res. 2000; 31 (5): 526-31.

2. Chen NJ, Chio II, Lin WJ, Duncan G, Chau H, Katz D, et al. Beyond tumor necrosis factor receptor: TRADD signaling in toll-like receptors. Proc Natl Acad Sci. 2008; 105(34):12429-34

3. Gupta A, Mazumder UK, Kumar RS, Kumar TS. Anti-tumor activity and antioxidant role of Bauhinia racemosa against Ehrlich ascites carcinoma in Swiss albino mice. Act Pharm Sin. 2004; 25(8): 1070-6.

4. Bi G, Jiang G. The molecular mechanism of HDAC Inhibitors in anticancer effects. Cell Mollmmunol. 2006; 3(4): 285-90.

5. Ghoshal PK, Thakur S. Structural features of the acidic polysaccharide of Spondias pinnata gum exudate. Carbohyd Res. 1981; 98(1): 75-83.

6. Bibitha B, Jisha VK, Salitha CV, Mohan S, Valsa AK. Antibacterial activity of different plant extracts. Indian J Microbiol. 2002; 42(4): 361-3.

7. Mahanta RK, Rout SD, Sahu HK. Ethnomedicinal plant resources of Similipal biosphere reserve, Orissa, India. Zoos Print J. 2006; 21(8): 2372-4.

8. Bibhanshu H, Santanu B, Nripendranath M. Antioxidant and free radical scavenging activity of Spondias pinnata. BMC Complement Altern Med. 2008; 8(63): $1-10$

9. Ellman GL. Tissue sulphydryl groups. Arch Biochem Bioph. 1959; 82(1): 70-7.

10. Koracevic D, Koracevic G, Djordjevic V, Andrejevic S, Cosic V. Method for the measurement of antioxidant activity in human fluids. J ClinPathol. 2001; 54(5): 356-61.

11. Irzyk GP, Fuerst EP. Purification and characterization of a glutathione S transfer- ase from benoxacor-treated maize (Zea mays). Plant Physiology 1993; 102(3) 803-10.

12. Buege JA, Aust SD. Microsomal lipid peroxidation. Methods Enzymol. 1978; 52: 302-10.

13. Rao GM, Rao AV, Raja A, Rao S, Rao A. Lipid peroxidation in brain tumours. Clinica Chimica Acta International Journal of Clinical Chemistry 2000; 302(1): 205-11.

14. Sudarshan Reddy C, Beena Shetty V, Gayathri Rao M. Modulatory effect of Spondias pinnata bark extract on intestinal MPO and sucarse activity in etoposide induced rat model for mucusitis. Int J BiolPharma Res. 2014; 5(5): 396-2.

15. Esfahani A1, Ghoreishi Z, Nikanfar A, Sanaat Z, Ghorbanihaghjo A. Influence of chemotherapy on the lipid peroxidation and antioxidant status in patients with acute myeloid leukemia. Acta Med Iran. 2012; 50(7): 454-8.

16. Josephy PD. Genetic variations in human glutathione transferase enzymes: significance for pharmacology and toxicology. Hum Genomics Proteomics 2010 2(1): 22-9.

17. HMR Rm. Regulation of hepatic glutathione synthesis: current concepts and controversies. The FASEB Journal 2011; 8: 901-13.

18. Akuyam SA, Uchenna OK, Adamu A, Aliyu IS, Mai A, Dawotola DA, et al. Liver function tests profile in cancer patients on Cytotoxic chemotherapy: a preliminary report. Niger Postgrad Med J. 2011; 18(1): 34-3.

19. Morrow PK, Tarrand JJ, Taylor SH, Kau SW, Theriault RL, Hortobagyi GN, et al. Effects of chronic hepatitis $\mathrm{C}$ infection on the treatment of breast cancer patients. Ann Oncol. 2010; 21(6): 1233-6.

20. Akuyam SA, Uchenna OK, Adamu A, Aliyu IS, Mai A, Dawotola DA, et al. Liver function tests profile in cancer patients on cytotoxic chemotherapy: a preliminary report. Niger Postgrad Med J. 2011: 18(1): 34-3.

\section{PICTORIAL ABSTRACT}

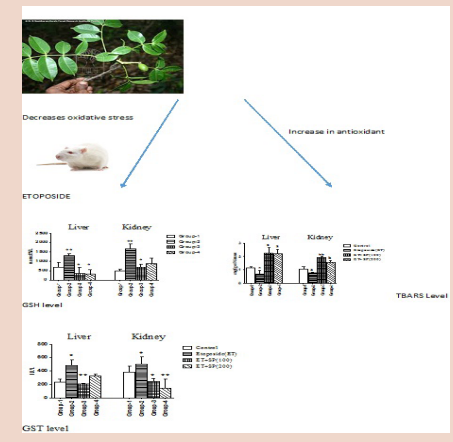

\section{SUMMARY}

- S. pinnata extract was more potent in inhibiting the oxidative stress and is reflected by the reduction in TBARS levels

- S. pinnata extract also restored GSH level, one of the potent antioxidant suggesting one of the mechanism preventing the oxidative stress developed due to etoposide.

- Significant decrease in GST levels shows the involvement of S. pinnata extract in detoxification process.

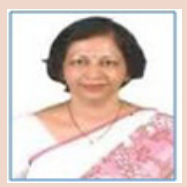

\section{ABOUT AUTHORS}

Beena Shetty: Obtained her Ph.D degree from Kasturba medical college, Manipal,Mysore university Mysore in 1987. Currently, she is Professor of Biochemistry, at Kasturba Medical college, Mangaluru, Manipal university.

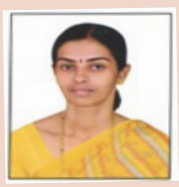

Gayathri Rao: Is Associate Professor in Biochemistry, at Kasturba Medical college mangaluru, Manipal University She has obtained her Ph.D degree in 1999 from Manipal Academy of Higher Education, Manipal. Currently her research focused on evaluation of therapeutic and preventive solutions from natural products against cancer and mucositis 